\title{
Isolation of Flavonoid Constituent from Launaea procumbens Roxb. by Preparative HPTLC Method
}

\author{
Gaurav J Mishra* M.N.Reddy and Jagruti S Rana \\ Shree Bapalal Vaidhya Botanical Research Center, Department of Biosciences, Veer Narmad South \\ Gujarat University, Surat, Gujarat, India
}

\begin{abstract}
There are a numbers of bioactive compounds in plants, such as alkaloids, tannins, flavonoids, sterols, triterpenes, etc., noted to have the major role in nutrition, physiology and control of diseases. Flavonoids constitute one of the most characteristic classes of compounds in higher plants. The foremost important task in this paradigm is the screening of these compounds in the plants. The chromatographic study of the compounds serves to be a very useful and reliable source in the process of bioactive compounds screening in plants. According to the ethnobotanical information, it has been reported that the plant Launaea procumbens possesses the anticancer potential. Hence in the present study, an attempt has been made to identify the flavonoid constituent of Launaea by using TLC and chemical derivatization method. Further, the isolation of the same compound is carried out by preparative HPTLC using the standardized solvent system viz., ethyl acetate: formic acid: glacial acetic acid: water (12.1: 1.3: 1.1: 2.8). The confirmation of the isolation was done by IR Spectroscopy.
\end{abstract}

Keywords-Preparative HPTLC, Isolation of Flavonoid, Launaea procumbens Roxb. , Solvent system for Flavonoid separation.

\section{INTRODUCTION}

Chemical compounds that occur naturally in plants are responsible for the color and organoleptic properties in the plants, such as deep purple color of blueberries and smell of garlic. These chemicals are called as the secondary metabolites or phytochemicals. The term, phytochemicals, is generally used to refer to those chemicals that may have biological significance but have not been established as essential nutrients. Phytochemicals have been used as drugs since long in the past. Many of the medicinal plants have been characterized for secondary metabolite screening and their possible use in the chemotherapy. Recent studies are involved in the identification and isolation of new therapeutic compounds of medicinal importance from the plants for specific diseases ${ }^{[1-4]}$.

There are a numbers of bioactive compounds in plants, such as alkaloids, tannins, flavonoids, sterols, triterpenes, etc., noted to have the major role in nutrition, physiology and control of diseases ${ }^{5-}$ 7]. Flavonoids are a large family of compounds synthesized by plants that have a common chemical structure. Flavonoids are poly-phenolic compounds possessing 15 carbon atoms and two benzene rings joined by a linear three carbon chain which may be further divided into subclasses as shown in Table I. Flavonoids constitute one of the most characteristic classes of compounds in higher plants, where they can be easily recognized as flower pigments in angiosperms. However, their occurrence is not restricted to flowers only, but include all the parts of a plant. Flavonoids are also known to play an important role in giving resistance to the plant species, such as rotenone, which is a isoflavonoid, serves to be an effective insecticide. The possible effect of isoflavonoids on human health is also extensively investigated especially in the prevention of cancer and in particular hormone dependent cancers such as breast cancer $^{[8-12]}$. In addition, consumption of soy foods rich in isoflavones has been weakly associated with reduced colon cancer $^{[13-14]}$.

The foremost important task in this paradigm is the screening of these compounds in the plants. The chromatographic study of the compounds serves to be a very useful and reliable source in the process of bioactive compounds screening in plants. This made the authors to adapt the highly reliable, basic chromatographic screening of the plant for the flavonoid constituents, refers to as the Thin Layer Chromatography and High Performance Thin Layer Chromatography on the plant Launaea procumbens Roxb. The further isolation of the separated compound has been carried out by the preparative HPTLC method and the final separation was confirmed by the Infrared spectroscopy followed by the Ultraviolet - Visible Spectroscopy. 
The genus Launaea belongs to the family Asteraceae. The plants in this genus are perennial to pauciennial herbs, small rosette shrubs, subshrubs, spinescent shrubs or annuals, all tap rooted and roots often shoot bearing. The leaves are sessile and commonly rosette, at least in juvenile plants. Launaea procumbens is a polymorphic perennial herb with shoot bearing roots (therefore plants often growing in groups), flowering up to $20-40 \mathrm{~cm}$ high, with basal leaf rosette and with (one to) several, rather week, procumbent to ascending-erect, leafy to leafless flowering stems; aging plants with woody (and often branched) base; rosulate leafy innovations at lower nodes of the stems often present.

\section{MATERIALS AND METHODS:}

Collection of Samples: Fresh plants was collected from, Shree Bapalal Vaidhya Botanical Graden, located in the Veer Narmad South Gujarat University Campus, Udhna Magdalla Road, Surat, Gujarat, India. Taxonomic identities of the plant were confirmed by the Taxonomists in Department of Biosciences, Veer Narmad South Gujarat University, Surat, Gujarat, India and the specimen voucher collection were preserved in the herbarium of the Department. The leaves from the plants were separated, washed under the running tap water and dried at $45^{\circ} \mathrm{C}$ in the oven. The dried leaves were then homogenized to fine powder and stored in the air tight container for future use.

Preparation of Extracts: Methanolic solvent extract was prepared by, adding $10 \mathrm{gm}$ of plant powder to $100 \mathrm{ml}$ of the solvent. The solution was then heated at $55^{\circ} \mathrm{C}$ on water bath for about $5 \mathrm{~min}$ and then sealed with the glass stopper and kept on the rotary shaker for $24 \mathrm{hrs}$. After 24hrs, the solution was concentrated under reduced pressure at $45^{\circ} \mathrm{C}$ using the rotary evaporator to $1 / 10^{\text {th }}$ of the initial volume $e^{[15]}$. This solution is then used for the further studies.

Chemicals and Reagents: All the chemicals and reagents including Methanol, Ethyl Acetate, Formic Acid and Glacial Acetic Acid were of Analytical Grade and purchased from Merck. The TLC silica plates were purchased from Merck of HPTLC Grade.

Screening of Flavonoids: The initial screening of the flavonoids in the methanolic extract was carried out with the basic qualitative test for flavonoids, where $0.5 \mathrm{ml}$ of the extract was mixed with $2 \mathrm{ml}$ of Conc. $\mathrm{H}_{2} \mathrm{SO}_{4}$ and few magnesium turnings ${ }^{[16-18]}$. Further, Thin Layer Chromatography of the extract was carried out with the modification in the method given by Wagner and Bladt, (1996). The solvent system was selected as, Ethyl Acetate: Glacial Acetic Acid: Formic Acid: Distilled Water (12.1: 1.3: 1.1: 2.8). In the TLC Screening procedure, a thin strip of 3 x $10 \mathrm{~cm}$ of TLC Silica Plate (TLC Silica gel $60 \mathrm{~F}_{254}$, Merck), was taken and impregnated with the fine drop of extract. The plate was then air dried and kept for the development in chromatographic chamber containing $10 \mathrm{ml}$ of the prepared solvent system. After the successful development, the plate was examined under the UV Chamber at $366 \mathrm{~nm}$. The presence of flavonoid constituent was confirmed by the chemical derivatization, where the developed plate was sprayed with $1 \%$ ethanolic solution of $\mathrm{AlCl}_{3}{ }^{[19]}$.

Preparative HPTLC of Extract: From the successful development of TLC plate with the prepared solvent system, the Preparative High Performance Thin Layer Chromatography of the methanolic extract was carried out on the CAMAG HPTLC System. Prior to sample application, $20 \mathrm{x}$ $10 \mathrm{~cm}$ HPTLC plate (HPTLC Silica gel $60 \mathrm{~F}_{254}$, Merck) was activated at $110{ }^{\circ} \mathrm{C}$ for $30 \mathrm{~min}$. $2000 \mu \mathrm{l}$ of the extract was then applied as a single band of $180 \mathrm{~mm}$ length on the activated HPTLC plate using a CAMAG automatic TLC sampler III (CAMAG, Switzerland). The plates were then developed with the $10 \mathrm{ml}$ of standardized solvent system, Ethyl Acetate: Glacial Acetic Acid: Formic Acid: Distilled Water (12.1: 1.3: 1.1: 2.8) in the twin trough chromatographic chamber. After the successful development, the plate was examined under the UV Chamber at $366 \mathrm{~nm}$.

Isolation of Flavonoid Constituent: The developed plate was then subjected for the isolation of the flavonoid constituent. The developed plate was then scaled marked with graphite tip from 1 $10 \mathrm{~cm}$, having $\mathrm{mm}$ scaling along the solvent system movement. The plate was kept in the UV Chamber at $366 \mathrm{~nm}$ and the flavonoid band was marked on the scales. The selected area was then scratched out along with the silica, with a sharp scalpel and collected in the eppendorf tube. The flavonoid constituent was then eluted from the silica gel with methanol and the content was pooled. The pooled content was concentrated by evaporating the methanol at room temperature and the final volume was kept $1 / 3^{\text {rd }}$ of the original and marked as FRC $1^{[20-21]}$. The FRC 1 was then cochromatographed with the crude extract for the confirmation of the band at the same Rf. 
Confirmation of Isolation of Flavonoids: The absorbance value of different bands in the crude extract after TLC separation was studied using the CAMAG automatic TLC scanner 3 for the most possible wavelength absorption. Further confirmation of the isolation of flavonoid was done by analyzing the FRC 1 in the UV-Visible Spectrophotometer for single peak and Infrared Spectrophotometer for major functional groups.

\section{RESULTS AND DISCUSSION}

Screening of Flavonoids: The initial screening of the flavonoids in the plant extract with basic preliminary procedures was the first step in the process. The screening of the flavonoids with primary phytochemical screening process revealed the presence of appreciable quantity of the flavonoids (Table II). The, Thin Layer Chromatography (TLC) process confirms the possible presence of flavonoids by revealing the fluorescent bands which on further derivatization gave yellow fluorescence on long wavelength $(360 \mathrm{~nm})$ and forms yellow colored zone when heated at $100^{\circ} \mathrm{C}$ for $5-10 \min ^{[19]}$.

Preparative HPTLC of Extract: The method of extraction of phytochemicals is the most important procedure in the development of pharmaceutical use of any plant species which is known or reported to have medicinal importance. Preparative HPTLC is one of the cheapest and yet highly reliable procedure in the fantasy of collecting pure compound from the crude plant extract. The crude extract revealed the brown, two light blue, bright blue fluorescent band and light brown band at $\mathrm{Rf}=$ $0.15,0.20,0.45,0.33$ and $0.82 \mathrm{~cm}$ respectively under the TLC scanner at $356 \mathrm{~nm}$ (Fig. 1). The clear, bright fluorescent band was considered to be of possible flavonoid at the $\mathrm{Rf}=0.33 \mathrm{~cm}$ (Fig. 2) and was selected for the isolation.

Isolation of the Flavonoid Constituent: The co-chromatographic screening of FRC 1 by HPTLC revealed the sharp, single, blue fluorescent band which was considered of flavonoid only at Rf $=0.33 \mathrm{~cm}$ under 366nm (Fig. 3).

Confirmation of Isolation of Flavonoid: The spectra comparison of the crude extract in TLC scanner revealed the maximum absorption of bands at $365-370 \mathrm{~nm}$ wavelength (Fig. 4), hence the spectrum analysis of FRC 1 was carried out with UV-Vis Spectrophotometer in the range of 200$800 \mathrm{~nm}$. The fraction, FRC 1 showed the presence of a single peak in the complete spectrum at approximately 370-380nm (Fig. 5). This resolves the approximate true confirmation of isolation of compound. Further the spectrum analysis of the FRC 1 in IR Spectrometry, revealed the strong and well resolved band which further confirms the separation. Also the presence of band at $3195.74 \mathrm{~cm}^{-1}$ indicates the possible presence of the free alkenes $(=\mathrm{CH})$ stretch having the region of 3100-3010 wavenumbers $\left(\mathrm{cm}^{-1}\right)$. The presence of band at $3423.47 \mathrm{~cm}^{-1}$ indicates the possible presence of phenols or alcohol (-OH) stretch having the region of 3650-3300 wavenumbers $\left(\mathrm{cm}^{-1}\right)$. The presence of band at $1652.32 \mathrm{~cm}^{-1}$ indicates the possible presence of aromatic compound $(\mathrm{C}=\mathrm{C}$ stretch) having the region of $\sim 1600$ wavenumbers $\left(\mathrm{cm}^{-1}\right)$ (Fig. 6).

\section{CONCLUSION}

From the above procedural workout, it can be clearly concluded that the plant Launaea procumbens does contain the flavonoids. The above stated procedure is therefore results to be very simple in the procedural workout isolation of compounds which seems to be very difficult in the case of plant extracts. This procedure, hence therefore, though being a very simple process, is remarkably very efficient for the purification of the compounds from crude extracts of the plants. Also the solvent system, standardized for the separation of flavonoids, founds to be suitable for the separation of flavonoids, where the clear separation of bands is one of the outmost tasks to be faced during the isolation of pure compounds from plant extracts. 
V. TABLES AND FIGURES

Table I: Common dietary flavonoids

\begin{tabular}{|c|c|c|}
\hline Flavonoids sub class & Dietary flavonoids & Some common food sources \\
\hline Anthocynadins & $\begin{array}{l}\text { Cyanidin, Delphinidin, } \\
\text { Malvidin, Pelargonidin, } \\
\text { Peonidin, Petunidin }\end{array}$ & $\begin{array}{l}\text { Red, blue and purple berries; } \\
\text { red and purple grapes; } \\
\text { red wine }\end{array}$ \\
\hline Flavanols & $\begin{array}{l}\text { Monomers (Catechins) } \\
\text { Catechin, Epicatechin, } \\
\text { Epigallocatechin, } \\
\text { Epicatechin gallate, } \\
\text { Epigallocatechin gallate } \\
\text { Dimmers and Polymers } \\
\text { Theaflavins, Thearubigins, } \\
\text { Proanthocyanidins }\end{array}$ & $\begin{array}{l}\text { Catechins: Teas (particularly green and white), } \\
\text { Chocolate, grapes, berries, apples } \\
\text { Theaflavins, Thearubigins: Teas (particularly } \\
\text { Black and oolong) } \\
\text { Proantocyanidins: Chocolate, apples, berries, } \\
\text { red grapes, red wine }\end{array}$ \\
\hline Flavanones & $\begin{array}{l}\text { Hesperetin, Naringenin, } \\
\text { Eriodictyol }\end{array}$ & $\begin{array}{l}\text { Citrus fruits and juices, e.g., oranges, } \\
\text { grapefruits, lemons }\end{array}$ \\
\hline Flavanols & $\begin{array}{l}\text { Quercetin, Kaempferol, } \\
\text { Isohamnetin }\end{array}$ & $\begin{array}{l}\text { Widely distributed: yellow onions, } \\
\text { scallions, kale, broccoli, apples, berries, teas }\end{array}$ \\
\hline Flavones & Apigenin, Luteolin & Parsley, thyme, celery, hot peppers \\
\hline Isoflavones & $\begin{array}{l}\text { Daidzein, Genistein, } \\
\text { Glycitein }\end{array}$ & Soybeans, soy foods, legumes \\
\hline
\end{tabular}

Table II: Screening of flavonoids by chemical method with other phytochemicals.

\begin{tabular}{|l|l|l|l|l|l|l|l|c|}
\hline $\begin{array}{l}\text { Sr. } \\
\text { No. }\end{array}$ & Alkaloids & Steroids & $\begin{array}{l}\text { Cardiac } \\
\text { Glycosides }\end{array}$ & Phenols & Tannins & Lignans & Flavonoids & Triterpenes \\
\hline 1. & ++ & + & + & ++ & + & - & ++ & - \\
\hline
\end{tabular}

"++" = Present in appreciable quantity; "+" = Present in low quantity, "-" = Absent.

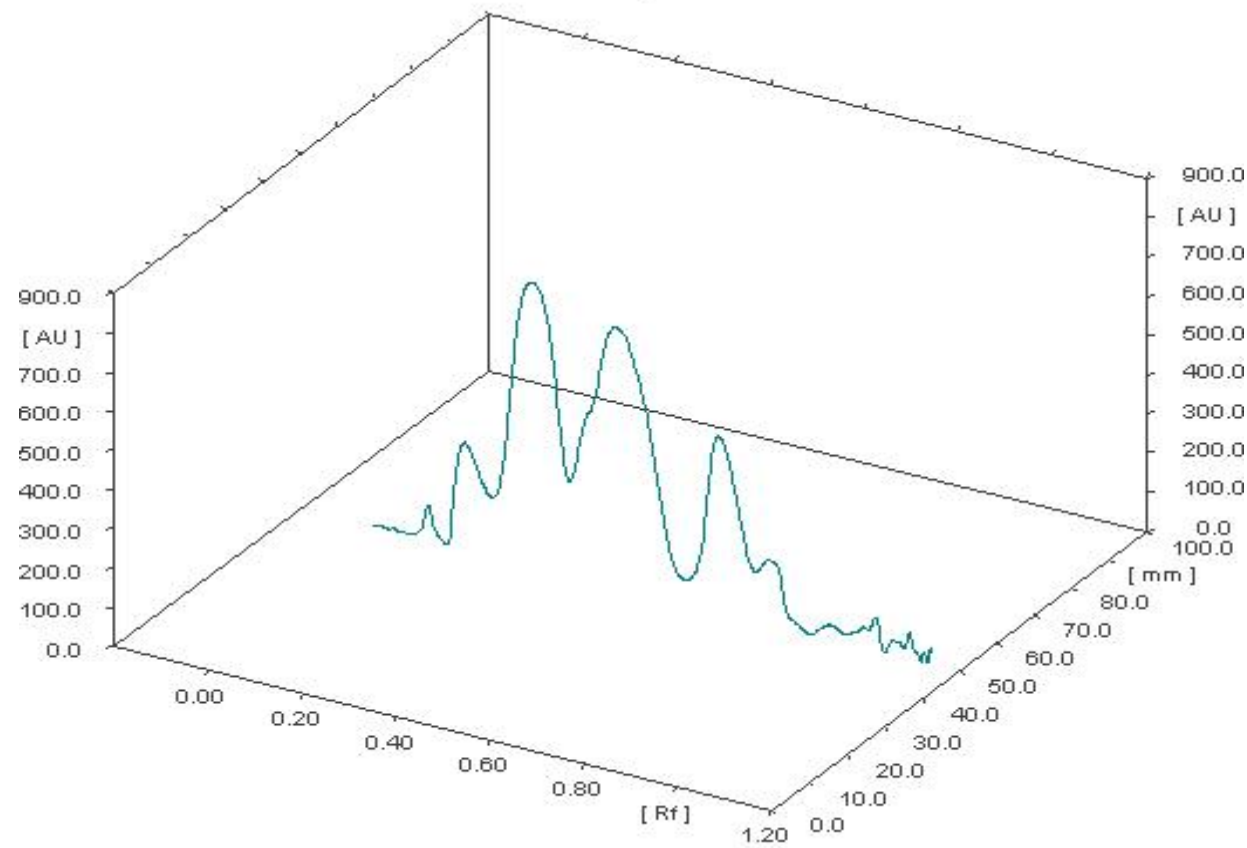

Figure 1: 3D graph of crude extract at 356nm wavelength 
Figure 2: Preparative HPTLC at 366nm (Methanolic Extract)

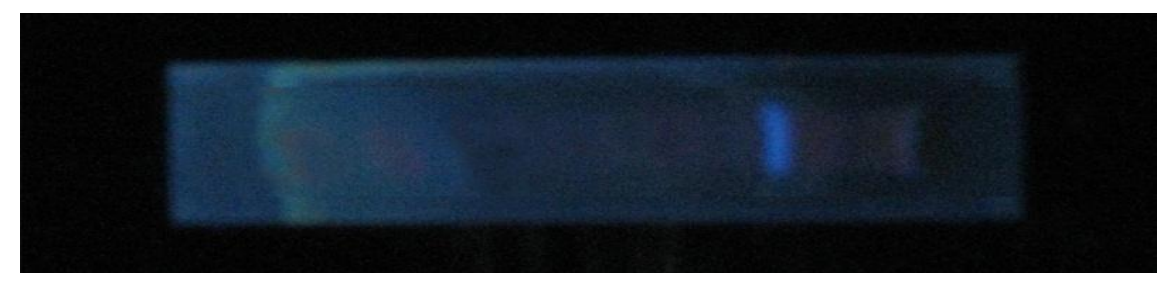

Figure 3: HPTLC of FRC 1 at 366nm

Spectra -comparison

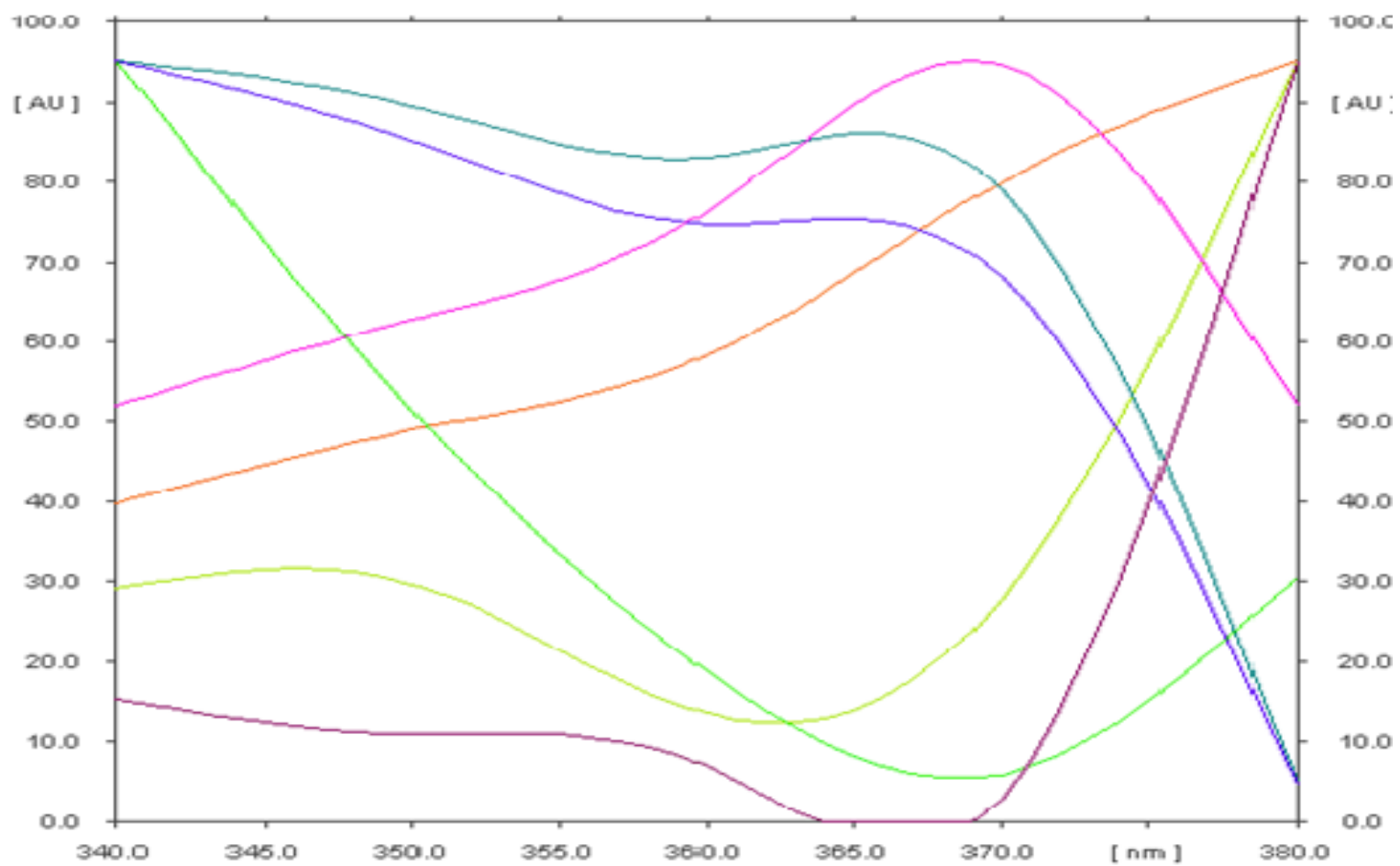

Figure 4: Spectra comparison of crude extract in TLC scanner 


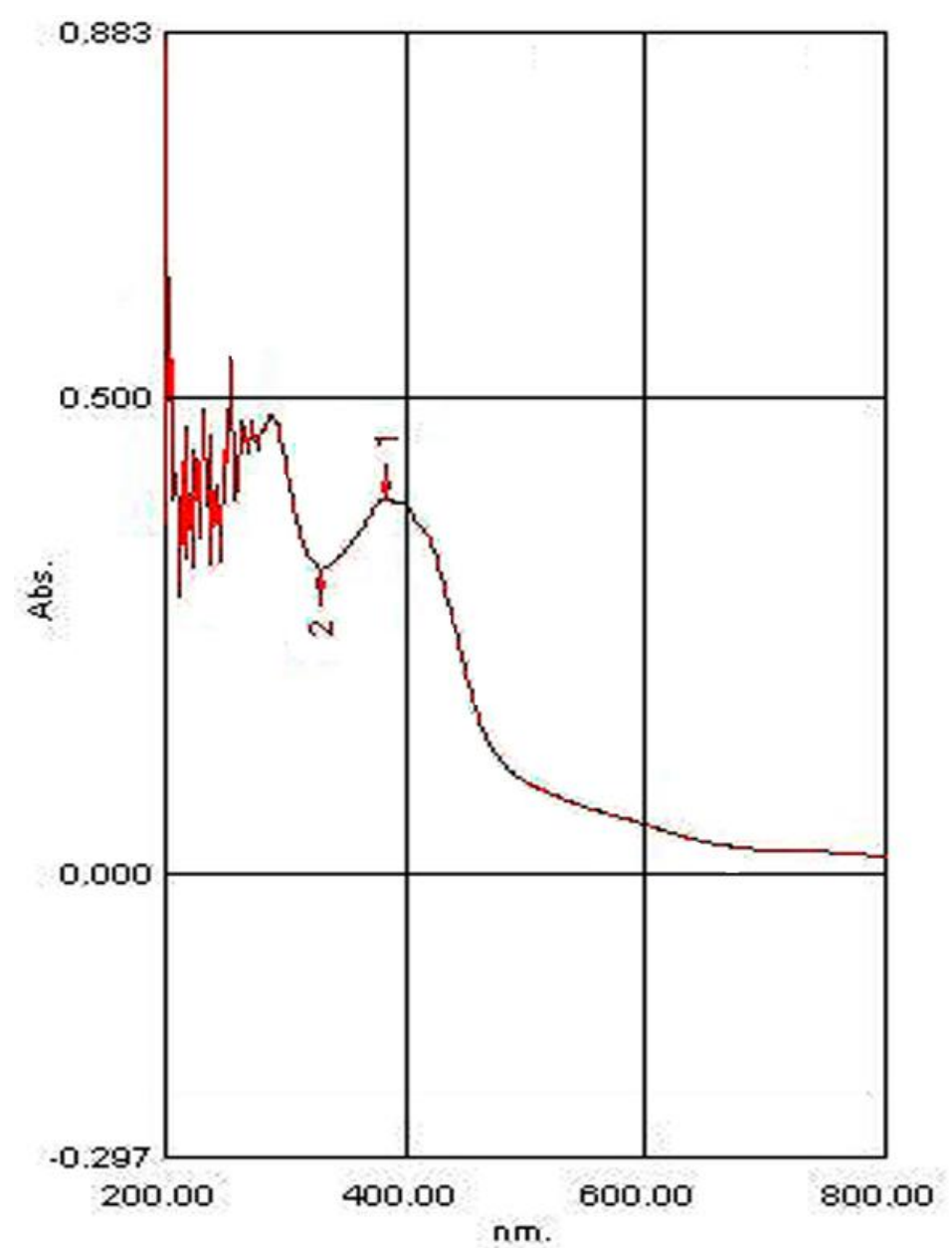

Figure 5: UV - Vis Spectra of FRC 1

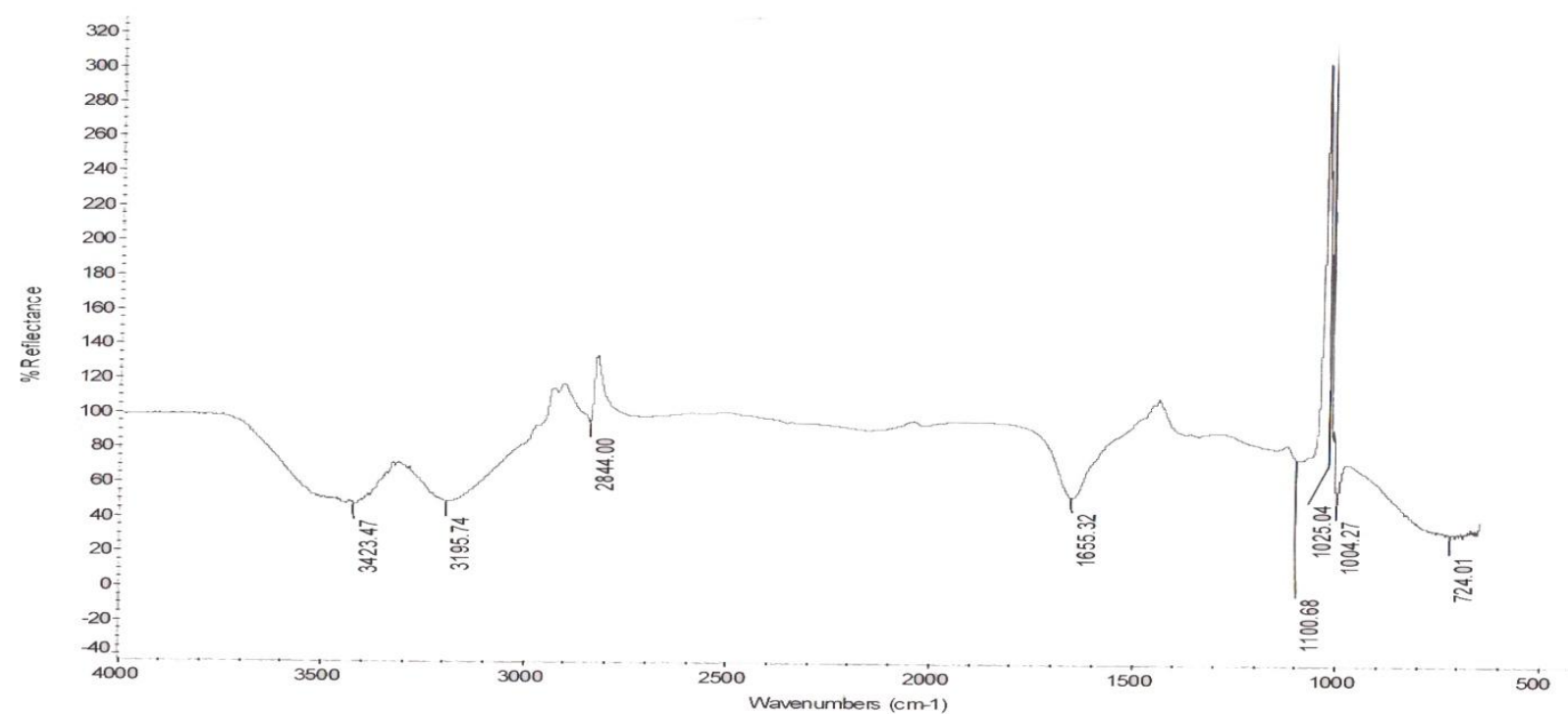

Figure 6: IR Spectra of FRC 1 


\section{REFERENCES}

[1]. Khan, M R, W Rizvi, G N Khan, R A Khan, and S Sheen. "Carbon tetrachloride induced nephrotoxicity in rats: Protective role of Digera muricata." J. Ethnopharmacol. 122 (2009): 91-99.

[2]. Khan, R A, M R Khan, and S Sahreen. "Evaluation of Launaea procumbens use in renal disorders: A rat model." $J$. Ethnopharmacol. 128 (2010a): 452-461.

[3]. Khan, R A, M R Khan, S Sahreen, and J Bukhari. "Prevention of CCl4 induced nephrotoxicity with Sonchus asper in rat." Food Chem. Toxicol. 23 (2010b): 1304-1321.

[4]. Sahreen, S, M R Khan, and R A Khan. "Evaluaion of antioxidant activities of various solvent extracts of Carissa opaca fruits." Food Chem. 122 (2010): 1205-1211.

[5]. Sahreen, S, M R Khan, and R A Khan. "Hepatoprotective effects of methanol extracts of Carissa opaca leaves on CCl4 induced damage in rat." BMC Compl. Alter. Med., (2011): 11-48.

[6]. Khan, R A, M R Khan, and S Sahreen. "Protective effect of Sonchus asper extracts against experimentally induced lung injuries in rats: A novel study." Exp. Toxicol. Pathol. 10 (2011a): 1-7.

[7]. Khan, R A, M R Khan, S Sahreen, S Jan, J Bokhari, and U Rashid. "Phytotoxic characterization of various fraction of Launaea procumbens." Afr. J. Biotech., (2011b): 5377-5380.

[8]. Cornwell, T, W Cohick, and I Raskin. "Dietary phytoestrogens and health." Phytochemistry, no. 65 (2004): $995-1016$.

[9]. $\quad$ Dixon, R A. "Phytoestrogens." Annu. Rev. Plant Biol. 55 (2004): 225-261.

[10]. Greenwald, P. "Clinical trials in cancer prevention: Current results and perspectives for the future." J. Nutr. 134, no. 12 (2004): 3507-3512.

[11]. Holzbeierlein, J M, McIntosh, and J B Thrasher. "The role of soy phytoestrogens in prostate cancer." Curr. Opin. Urol. 15 (2005): 17-22.

[12]. Magee, P J, and I R Rowland. "Phyto-oestrogens, their mechanism of action: Current evidance for a role in breast and prostate cancer." Br. J. Nutr. 91 (2004): 513-531.

[13]. $\quad$ Adelcreutz, H. "Phyto-oestrogens and canecr." Lancet Oncol. 3 (2002): 32-40.

[14]. Guo, J Y, X Li, and J D Browning. "Dietary soy isoflavones and estrone protect ovariectomized ERalphaKO and wild type mice from carcinogen induced colon cancer." J. Nutr. 134 (2004): 179-182.

[15]. Reddy, M N, and G J Mishra. "Preliminary phytochemical screening and antibacterial analysis of the leaf extracts of Launaea procumbens Roxb." International Journal of Phytopharmacology 3, no. 2 (2012): 147-151.

[16]. Harbone, J B. Phytochemical methods. London: Chapman \& Hill, 1973.

[17]. Harbone, J B. Phytochemistry. London: Academic Press, 1993.

[18]. Trease, G E, and W C Evans. Pharmacognosy. 13th. London: Bailliere Tindall Ltd, 1989.

[19]. Wagner, H, and S Bladt. Plant drug analysis: A thin layer chromatography atlas. 2nd. Springer, 1996

[20]. Markham, K. "Isolation techniques for flavonoids." In The flavonoids, by J B Harborne, T J Mabry and H Mabry. New York: Academic Press, 1975.

[21]. Hostettman, K, A Marston, and M Hostettman. Preparative chromatographic techniques: Applications in natural product isolation. 2nd. Berlin: Springer-Verlag, 1998. 